\title{
Science Academies' Refresher Course on Innovations in Genetics and Plant Breeding with Special Reference to Biotic and Abiotic Stress
}

at

PG and Research Department of Botany, Vivekananda College of Arts and Sciences for Women (Autonomous), Elayampalayam - 637 205, Tiruchengode, Tamil Nadu

06-18 November 2017

\author{
Sponsored by Indian Academy of Sciences, Bengaluru \\ Indian National Science Academy, New Delhi \\ The National Academy of Sciences, India, Allahabad
}

\begin{abstract}
A Refresher Course in "Innovations in Genetics and Plant Breeding with Special Reference to Biotic and Abiotic Stress" will be held at PG and Research Department of Botany, Vivekananda College of Arts and Sciences for Women (Autonomous), Elayampalayam, Tiruchengode, Tamil Nadu for two weeks from 6 to 18 November 2017 for the benefit of faculty involved in teaching undergraduate and postgraduate courses. The objective of this course is to improvize on teaching methodologies and also get familiar with basics to advanced laboratory techniques in life sciences including plant breeding. This course is sponsored by Indian Academy of Sciences, Bengalaru, Indian National Science Academy, New Delhi; The National Academy of Sciences, Allahabad. The participants of the refresher course will have hands-on experience with all of the advanced facilities available in the College.

Applications are invited from teachers with experience in teaching undergraduate and postgraduate courses in Life Sciences, Agriculture and Technology. Applications from highly motivated Research Scholars will also be considered. The maximum number of seats will be 35 . Teachers who wish to participate in the refresher course may apply through proper channel with the following details: name, date of birth, gender, Email, official and residential addresses, telephone numbers, academic qualifications, courses taught, affiliation, positions held and tenure. It is also essential to submit a brief statement (between 250 and 500 words) as to why they think the Course will help to improve their classroom teaching of Life Sciences. There will be NO applications fee/registration fee.
\end{abstract}

Applications should be submitted ONLINE by clicking the following link:

http://web-japps.ias.ac.in: 8080/Refreshcourse/RIGP.jsp

A print copy of the application must also be sent by speed post forward by the Head of the Institution. It should reach Dr. M Senthilkumar, Course coordinator, Refresher Course on "Innovations in Genetics and Plant Breeding with Special Reference to Biotic and Abiotic Stress", PG and Research Department of Botany, Vivekananda College of Arts and Sciences for Women (Autonomous), Elayampalayam - 637 205, Tiruchengode, Tamil Nadu

(Email: senthilkumar200572@yahoo.com; Mobile: 97154 73806). Out station candidates will be provided local hospitality and round trip bus/train (three-tier AC) fare by the shortest route as per the guidelines of Academy.

Course Director: Prof. R Uma Shaankar, Department of Crop physiology and School of Ecology and Conservation, University of Agricultural Sciences, GKVK, Bengaluru.

Last date for receipt of applications: 1 October 2017

Selected participants will be informed on 5 October 2017 